\title{
Research on Bearing Mechanism of Strut- and-Tie Model for Punching Failure of Independent Foundation Under Column
}

\author{
Jie DENG ${ }^{\text {a,1 }}$ \\ ${ }^{a}$ School of Civil Engineering and Architecture, Wuhan Polytechnic University, Xuefu \\ South Road No.68, Dongxihu, Wuhan, Hubei, China
}

\begin{abstract}
Through three-dimensional nonlinear finite element analysis, the punching failure's bearing mechanism of the independent foundation under column whose slab is the size of $0.8 \mathrm{~m} \times 0.8 \mathrm{~m} \times 0.3 \mathrm{~m}$ is obtained. The transfer mechanism of the foundation is spatial strut-and-tie model, where the reinforcements located in the link ranges between each adjacent corner of the slab are represented by ties, and the concrete distributed in the link ranges from the column bottom to four corners of the slab bottom are represented by struts. The indication of punching failure is that the concrete at the two ends of the struts reaches the shear-compression failure strength, and the punching cone is punched out relative to the slab, which has distinct punching failure features. A new spatial strut-and-tie model composed of four ties and four struts is proposed on the basis of clear bearing mechanism, which provides a new idea for the calculation of the punching bearing capacity of the independent foundation under column.
\end{abstract}

Keywords. Independent foundation under column, punching failur, bearing mechanism, nonlinear finite element

\section{Introduction}

Independent foundation under column (hereinafter referred to as "foundation") is an important structural component to ensure the safety of superstructure. Two problems [1] should be considered in the punching bearing capacity design of foundation. Because the quantities of foundation structure are relatively large, the first problem is how to reduce the amount of concrete and the cost of the project. Then, the second one is how to deal with the nonlinear deformation and the uneven distribution of stress at the bottom of the foundation, the complex distribution of cross-section stress, etc. The theory of strut-and-tie model (STM) is an extension of the lower-bound solution theorem of plastic mechanics. It is a good solution to sudden changes of geometrical conditions and prominent impact of punching shear. Based on the stress distribution of structural components, the principal compressive stress and the principal tensile stress are replaced by strut and tie respectively to form the truss system in this method. The bearing behavior of the structure is revealed by analyzing the truss system.

\footnotetext{
${ }^{1}$ Jie Deng, School of Civil Engineering and Architecture, Wuhan Polytechnic University, Xuefu South Road No.68, Dongxihu, Wuhan, Hubei, China.; E-mail: maria1009@163.com.
} 
Solution on the above-mentioned problems by using the strut-and-tie model theory [2] depends on the condition that the failure form of foundation is punching failure, which means that the failure form of foundation should be defined before studying the bearing mechanism of foundation. Therefore, in combination with the foundation model of punching failure in reference [2], this paper revealed the punching failure's bearing mechanism of foundation under axial load and provided a new idea for calculating the punching bearing capacity of foundation by nonlinear finite element numerical simulation.

\section{Bearing Mechanism of Foundation under Punching Failure}

By using the topological optimization function of in ABAQUS (TOFA) software [3], the transfer mechanism of the foundation was revealed. Besides, ADINA software [4] was used to validate the failure form of the foundation, and the failure mechanism was studied by concrete plastic compressive damage nephogram in ABAQUS.

\subsection{Modeling of Finite Element}

\subsubsection{Modeling by ABAQUS}

The topological optimization was carried out in linear elastic stage, so the foundation model was established in linear elastic stage. What's more, concrete plastic compressive damage nephogram was carried out in nonlinear stage, so the model was a nonlinear model.

Geometric dimensions: In ABAQUS, the size of the slab was $0.8 \mathrm{~m} \times 0.8 \mathrm{~m} \times 0.3 \mathrm{~m}$, and the size of the column was $0.2 \mathrm{~m} \times 0.2 \mathrm{~m} \times 0.2 \mathrm{~m}$. The soil model whose thickness was $2.4 \mathrm{~m}$ was square with a side length of $2.4 \mathrm{~m}$ (2 3 times the maximum size of the slab). The concrete's Young's Modulus and Poisson's Ratio were $2 \times 10^{9} \mathrm{~N} / \mathrm{m}^{2}$ and 0.2 , respectively. The soil's Young's Modulus and Poisson's Ratio were $2 \times 10^{7} \mathrm{~N} / \mathrm{m}^{2}$ and 0.2 , respectively.

Constitutive relations and element types: For nonlinear analysis, the plastic damage model was used for concrete. The concrete grade was C25 whose specific parameters were taken according to the relevant ones in the Code for Design of Concrete Structures (GB 50010-2010), and the element type was three-dimensional solid element. In addition to reference [2], soil was added. The soil adopted threedimensional solid element, and Mohr-Coulomb model, whose Young's Modulus, Cohesion, Friction Angle, and Poisson's Ratio were $2 \times 10^{7} \mathrm{~N} / \mathrm{m}^{2}, 1 \times 10^{6} \mathrm{~N} / \mathrm{m}^{2}, 35^{\circ}$ and 0.2 , respectively. According to reference [2], the uniform grid reinforcement at the slab bottom was utilized, there were 18 HRB400 reinforcements with the diameter $14 \mathrm{~mm}$, which adopted Bilinear Elastic-Plastic model and truss element. Since the thickness of the protective layer was not clearly provided in reference [2], 70mm was taken according to the Code for Foundation Design of Buildings (GB 50007-2011). The specific size was shown in figure 1 . 


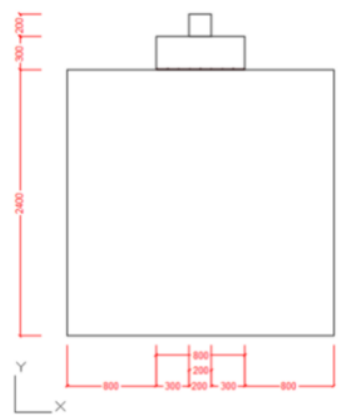

(a) Model evolution.

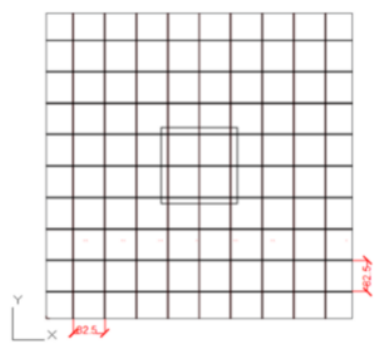

(c) Reinforcement grid plane.

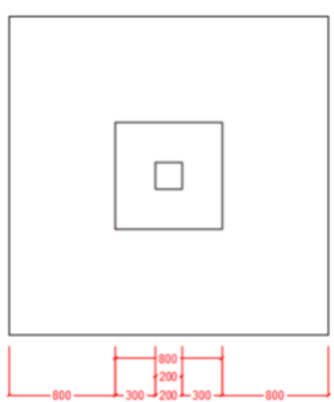

(b) Model plan.

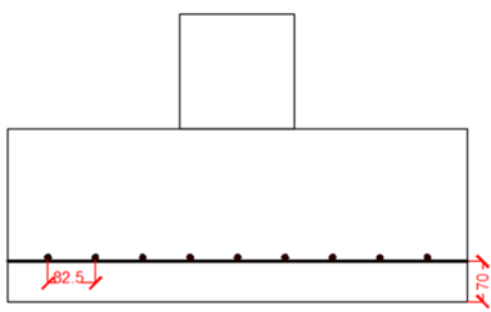

(d) Evolution of reinforcement grid.

Figure 1. Dimension and reinforcing details of the model. (Note: Dimensions in $\mathrm{mm}$ )

Contacts, boundary conditions and loading method: The rigid link without relative slide was adopted between the column bottom and the slab top; The intersection of the slab bottom and the soil top was the same as the above. Due to the immature bond slip constitutive relation at present and uncontrollable results, the bond slip between reinforcement and concrete was not considered. Therefore, the bond slip between reinforcement and concrete adopted rigid link. The bottom of the soil was the fixed end.

The normal displacement constraints were applied to the four faces of the soil and the slab, and the displacement constraints with 6-degree freedom were applied to the bottom of the soil.

Uniformly vertically downloads distributed load was applied to the top of the column. In nonlinear analysis stage, remain $10 \mathrm{kN}$ per analysis step until the iteration did not converge.

\subsubsection{Modeling by ADINA}

This part is nonlinear study, so the model was established around the nonlinear analysis.

Geometric dimensions: The model dimensions are consistent with those in ABAQUS.

Constitutive relations and element types: The concrete adopted smeared crack model [5] and its failure criterion was three-dimensional failure criterion. The concrete grade, parameters and element type were consistent with ABAQUS, respectively. Mohr-Coulomb model was also used in soil, and the parameters and element type were consistent with ABAQUS. The reinforcement, parameters and element types were also 
consistent with ABAQUS. The thickness of concrete protective layer was also the same as the above.

Contacts, boundary conditions and loading method: The contacts and the boundary conditions were the same with ABAQUS, also, the loading method was same with the nonlinear phase of ABAQUS.

\subsection{Transfer Mechanism of Foundation under Punching Failure}

The transfer mechanism of the foundation was revealed by using TOFA with removing the elements of low stress level and leaving the main transfer elements in the process of topological optimization. The process of topological optimization was shown in figure 2.

1) Prior to the optimization: As shown in figure 2 (b), the elements in the four corners at the top of the slab were firstly deleted, which indicated that this part of concrete had small stress level.

2) Continuing to optimization: As shown in figures 2(c)-(d), after the middle elements of the foundation was deleted, a cavity which was similar to a spatial shell structure was formed in the belly of the slab. The shell part formed from the column bottom to the slab bottom beared compressive stress, and the reinforcement and concrete at the slab bottom beared tensile stress together. The two parts together formed a closed spatial shell, showing a certain transfer mechanism of the tie and arch.

3) End of optimization: As shown in figures 2(e)-(f), the transfer mechanism of the foundation was spatial strut-and-tie model (SSTM). The ranges from the column bottom to four corners of the slab bottom exhibited larger principal compressive stress, and this part of concrete can be represented by strut; The tensile stress mainly distributed at the bottom edge of the slab and most of it was beared by reinforcements, which can be represented by tie. Thus, the transfer mechanism of tie and arch was more significant. By now, the transfer mechanism of the foundation is spatial strut-and-tie model, where the reinforcements located in the link ranges between each adjacent corner of the slab are represented by ties, and the concrete distributed in the link ranges from the column bottom to four corners of the slab bottom are represented by struts.

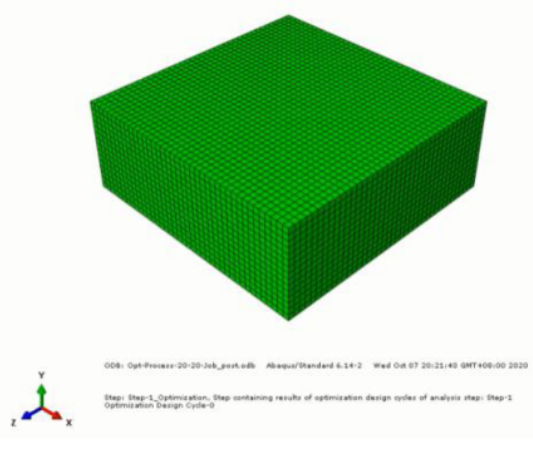

(a) Initial structure.

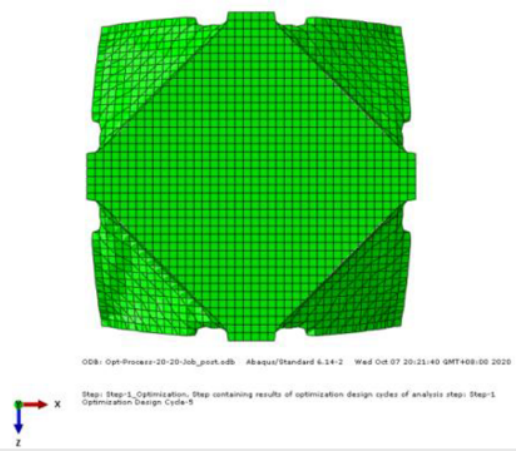

(b) Prior to the optimization. 

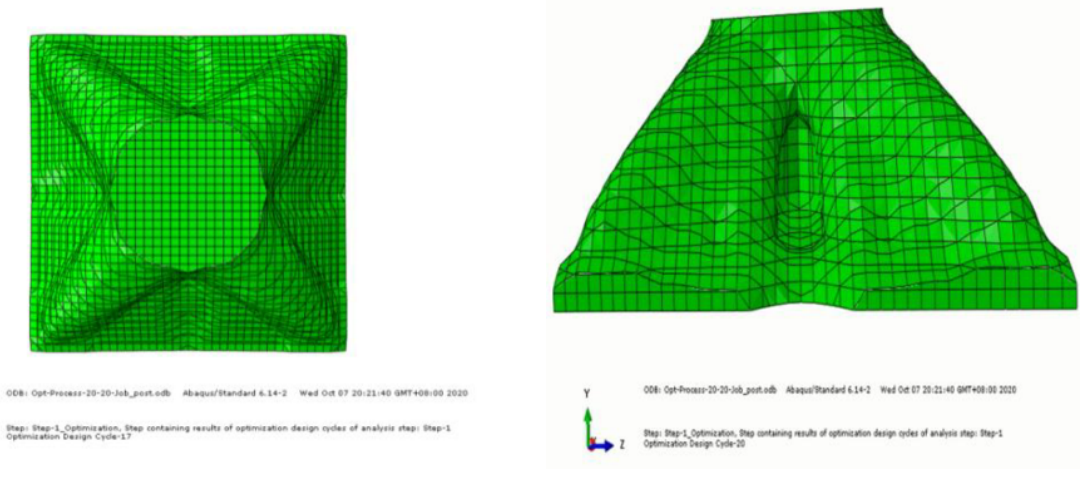

(c) Medium-term of the optimization-1.

(d) Medium-term of the optimization-2.
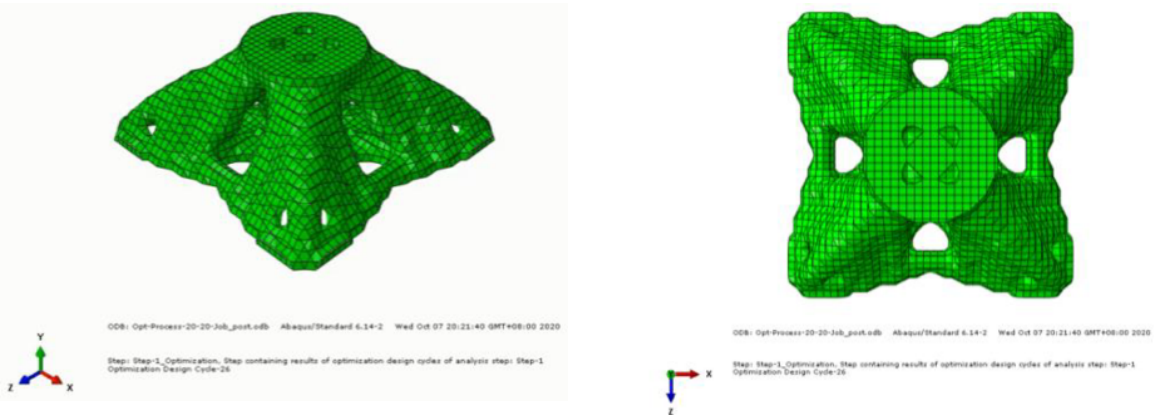

(e) End of the optimization-1.

(f) End of the optimization-2.

Figure 2. Optimization process.

\subsection{Axial Dimension of Foundation SSTM under Punching Failure}

According to the above-mentioned transfer mechanism of the foundation under punching failure, strut-and-tie model's axial dimension of the foundation under punching failure can be achieved. As shown in figure 3, it is a spatial truss system composed of four struts and four ties, where the concrete distributed in the link ranges from the column bottom to the four corners of the slab bottom are represented by struts whose cross-section are applied by the principal compressive stress, and the reinforcements located in the link ranges between each adjacent corner of the slab are represented by ties for bearing principal tensile stress. This transfer mechanism reflects the transfer path inside the foundation, and also meets the condition of internal force balance. 


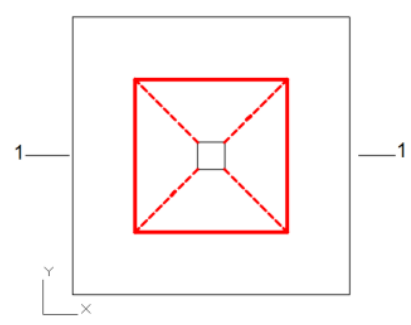

(a) Top view of axial dimension.

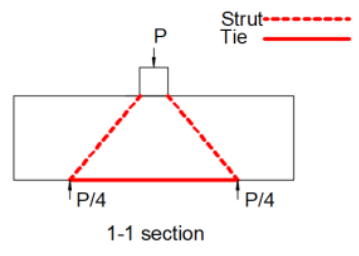

(b) 1-1 Section of axial dimension.

Figure 3. Axial dimension of strut-and-tie model.

\subsection{Failure Mechanism of Foundation under Punching Failure}

\subsubsection{Failure Form of Foundation}

Through ADINA software's post-processing, the extension of cracks can be shown clearly. As shown in figure 4, the cracks along the angle of nearly $50^{\circ}$ distributed from the column bottom to the slab bottom to form the punching cone. The indication of punching failure was that the concrete at the two ends of the struts reached the shearcompression failure strength, and the punching cone was punched out relative to the slab, which had distinct punching failure features. The failure features indicates that the punching sections are exactly where the struts are located, and the link ranges between each adjacent corner of the slab are exactly where the ties are located. It was validated that this conclusion is in good agreement with SSTM obtained in 2.3.

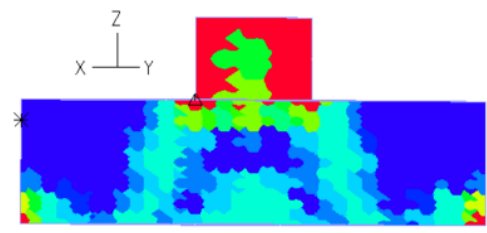

Figure 4. Cracks' extension in ADINA's post-processing.

\subsubsection{Failure Process of Foundation under Punching Failure}

As shown in figure 5, by the concrete plastic compressive obtained from ABAQUS and the crack extension achieved from ADINA, punching failure of foundation can be divided into the following three stages:

1) Stage before generation of split oblique cracks: As shown in figure 5(a), when the load reaches about $9 \%$ of the ultimate load, the cracks are not at the top of the slab but in the four corners of slab bottom. As shown in figure 5(b), with the load increasing to nearly $40 \%$ of the ultimate load, cracks appear at the contact between the column and the slab, and develop around the column. Besides, split oblique cracks doesn't appear in the belly of the foundation. Although there are some cracks in the bottom of the slab, the number of cracks is few.

2) Stage of split oblique cracks' generation and development: as shown in figures 5(c)-(d), when the load reaches about $70 \%$ of the ultimate load, a jujube-shaped inclined strut is formed in the slab and the concrete plastic compressive damage in the 
belly of the inclined strut was more serious than the other parts, which indicates that the splitting cracks will be generated here to have the oblique cracks formed throughout the whole strut. As shown in figures 5(e)-(f), when the load reaches about $80 \%$ of the ultimate load, it can be seen from the concrete plastic compressive damage nephogram that the concrete in the belly and surrounding of the struts is seriously damaged. In addition, the struts have undergone splitting in the belly and the oblique cracks extend to the slab bottom and the column bottom, respectively. Thus, the foundation entered the stage of punching failure.

It is worth pointing out that all of the above is basically consistent with the generation and development of the strut splitting crack in reference [6].

3) Punching failure stage: As shown in figures $5(\mathrm{~g})-(\mathrm{h})$, when the ultimate load is reached, the strut splitting cracks connect to form the enclosed shell cracks, which is exactly consistent with the transfer mechanism analysis of the spatial shell in the above-mentioned figures 2(c)-(d). Corresponding to these, the cracks developed from the belly of the strut to the slab bottom and column along the angle of nearly $50^{\circ}$, respectively. When, the concrete at two ends of the struts reaches the shearcompression failure strength, the punching cone is punched out from the slab.

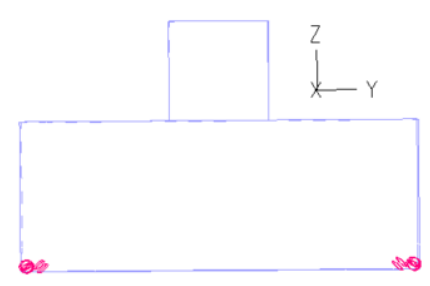

(a) Crack distribution of foundation at about $9 \%$ of the ultimate load.

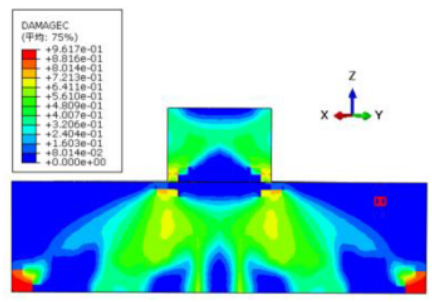

(c) Concrete plastic compressive damage nephogram at about $70 \%$ of the ultimate load strut at load.

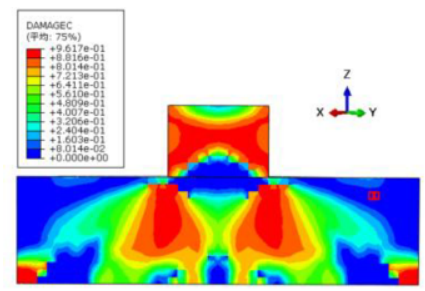

(e) Concrete plastic compressive damage nephogram at about $80 \%$ of the ultimate load.

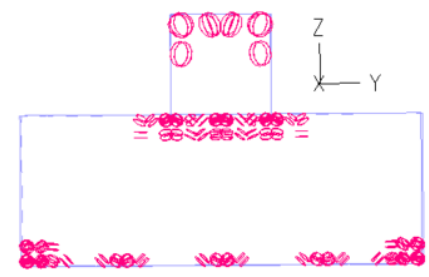

(b) Crack distribution of foundation at about $40 \%$ of the ultimate load.

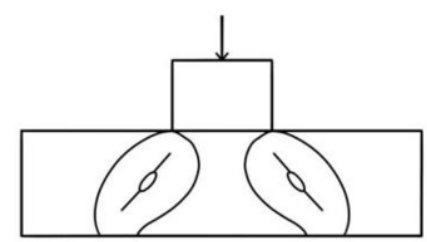

(d) Inclined strut in the shape of jujube the splitting in the midpart of the about $70 \%$ of the ultimate.

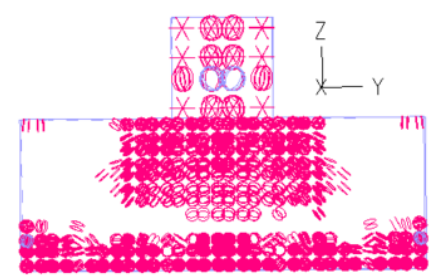

(f) Crack distribution of foundation at about $80 \%$ of the ultimate load. 


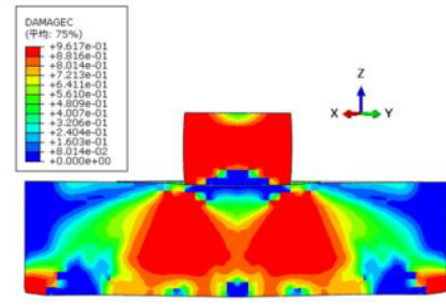

(g) Concrete plastic compressive damage nephogram at about the ultimate load.

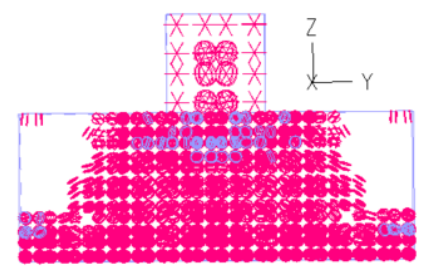

(h) Crack distribution of foundation at about the ultimate load.

Figure 5. Failure process of foundation under punching failure from finite element.

\section{Conclusions}

1) The transfer mechanism of the foundation under punching failure is SSTM. It is composed of four struts connecting the column bottom and the slab bottom and four ties connecting each adjacent corner of the slab.

2) The punching failure of the foundation begins with the splitting of the strut and ends with the punching cone from the development of the penetrating cracks induced by the splitting.

\section{References}

[1] Gu ChY, Luo MY, et al. Review of basic research and engineering design status of concrete independent foundation. Building Structures. 2017 Jun; 47(S1): 1091-1095.

[2] Campione G, Cannella F and Cavaleri L. Practical calculation models for column footing and comparison with experimental data. Practice Periodical on Structural Design and Construction. 2017 Aug; 22(4).

[3] E XH. Study on topology optimization method of progressive structure in typical d--zone of reinforced concrete structure. Wuhan Polytechnic University, China. 2018 May; 67.

[4] Qiu ZhT. Simulation of nonlinear punch-shear damage process of thick raft foundation. Lanzhou University of Technology, China. 2007 May; 76.

[5] Wang H. ADINA Nonlinear finite element analysis of concrete crack. Engineering Technology Research. 2018 Jul; (07): 26-27.

[6] Guo HL. Evaluation of column load for generally uniform g-ird reinforced pile cap failing in punching. ACI Structural Journal. 2015 Mar; (2): 123-134. 